\title{
COMPLIANCE WITH STANDARD PRECAUTIONS IN INPATIENT HEALTHCARE SETTINGS IN THE CZECH REPUBLIC: A CROSS-SECTIONAL SURVEY
}

\author{
Andrea Pokorná1, , Dana Dolanová1,, Michal Pospíšil ${ }^{1,2}$, Petra Búřilová',, Jan Mužík ${ }^{1,2}$ \\ 'Department of Nursing and Midwifery, Faculty of Medicine, Masaryk University, Brno, Czech Republic \\ ${ }^{2}$ Institute of Health Information and Statistics of the Czech Republic, Prague, Czech Republic
}

\begin{abstract}
SUMMARY
Objective: The study evaluates compliance with declared hygienic standards carried out by healthcare professionals in clinical practice within their scope of direct patient care and the maintenance of medical tools and devices in healthcare facilities in the Czech Republic.

Methods: Cross-sectional questionnaire study focused on the standards of safe health care. All 80 addressed healthcare providers were also involved in the 2018 Adverse Event Reporting System (AERS) pilot project. Responses were scored on a 6-level scale, from "always" (100 points) to "never" (0 points). The evaluation was performed according to the frequency of responses and the average index (max. 100 points). Data analysis was performed using IBM SPSS Statistics version 22 (level of significance 1\% and $5 \%$ ).

Results: There were statistically processed 2,016 questionnaires (100\%). Most respondents stated their job classification as non-medical healthcare professionals (NHP) working at a patient's bedside (73\%), physicians (16\%), or other NHP (11\%). As per their medical specialty, $43 \%$ of the respondents practice internal medicine, $28 \%$ surgery, $14 \%$ psychiatry, $9 \%$ long-term inpatient care, and $6 \%$ stated other fields of medicine. The lowest declared compliance was registered in the statement "I use a face mask when exposure to air-transmitted pathogens is anticipated" (rating index 80 points). The highest compliance (99.4 points) was registered in the statement: "I discard used sharp materials into sharps containers."

Conclusion: In the surveyed healthcare facilities within the Czech Republic, overall compliance with hygiene standards is at a good level. Declared differences in compliance with hygiene standards in the selected items of the questionnaire are influenced by multiple factors. Generally, a higher level of compliance is linked to increasing age, years of practice, and a higher level of education. When comparing professional groups, a higher level of compliance with hygiene standards was registered in the NHP group.
\end{abstract}

Key words: healthcare standards, safe health care, hygienic precautions, infection, prevention, healthcare providers

Address for correspondence: A. Pokorná, Masaryk University, Faculty of Medicine, Brno, Department of Nursing and Midwifery, Kamenice 753/5, 62500 Brno, Czech Republic. E-mail: apokorna@med.muni.cz

https://doi.org/10.21101/cejph.a5942

\section{INTRODUCTION}

The number of infections associated with the hospital environment in clinical practice is increasing. Compliance with hygiene precautions is the most critical factor influencing the transmission of hospital-acquired infections, also called health care-associated infections (HAI). Hands of healthcare professionals are undoubtedly the most common media for pathogen transmission. In the Czech Republic, the most commonly transmitted infections in healthcare settings are scabies, viral hepatitis and tuberculosis. In this manner, the most affected profession groups are nurses, auxiliary personnel, physicians, and cleaners. Although there is an ongoing trend of decreasing the incidence of all previously mentioned diseases, preventative measures against their transmission shall still be essential $(1,2)$. Safe health standards, hereinafter referred to as standard precautions (SP), have been developed to protect both professionals and patients and others in the patient care process from the effects of microorganisms.
Standard precautions define the minimal infection prevention procedures applicable to all stages of patient care, regardless of whether the infection is confirmed or not. Standard precautions are based on risk assessment, common sense, and proper use of personal protective equipment that protects healthcare service providers from infection and prevent the spread of infection from patient to patient (3). Accidental exposure to blood and/or other body fluids poses a serious threat to public health amongst healthcare professionals, and it also increases the risk of transmission of blood-borne viruses. Infections from occupational exposure can be primarily prevented by strict infection control measures (4). The questionnaire study was focused on the evaluation of compliance with hygienic standards carried out by healthcare professionals within the scope of providing direct patient care and in the care of medical tools and instruments. The fact that there is no standardized national hygiene monitoring system in the Czech Republic has been another motivation for the research, also aiming to obtain input knowledge. 


\section{MATERIALS AND METHODS}

Standardized questionnaire Standard Precautions (SP) used as a research instrument contains 10 structured questions and was originally created by G. Efstathiou et al. (5). The questionnaire was then translated from English into Czech by the method of double-blind translation. Subsequently, the authors of the study added several items of socio-demographic nature (age, gender, highest level of education, years of practice, field of medicine, type of hospital operation, job position). The standardized part of the questionnaire contained non-neutral response choice items on the Likert scale ("always", usually", "often", "sometimes", "seldom", "never") - these have been quantified and scored with the respective index values $(100,80,60,40,20,0)$. Respondents assessed the compliance degree by indicating the frequency of compliance with basic hygiene requirements and selecting their answer in the positive ("always", "usually", "often") or negative ("never", "seldom", "sometimes") response scale. Informed consent to the processing of the personal data for research purposes was included at the beginning of the questionnaire. Without the agreement in consent, the respondents were not allowed to continue filling in the questionnaire form.

All 80 addressed healthcare providers (HCPs) in the Czech Republic were also involved in the 2018 project Adverse Event Reporting System (AERS), i.e. a system reporting adverse events on the national level (6). The questionnaire form was distributed electronically (link to the electronic form) by a verified AERS contact person, usually a quality manager of the participating facility. All personnel in a particular healthcare facility were approached. The questionnaire was filled in during the shift. There was no feedback needed after the questionnaire was answered. The approached facilities had signed the agreement among the directors of involved hospitals and the Institute of Health Information and Statistics (IHIS), and the study was part of the AERS activities. Thus, the respondents had been informed that their participation was voluntary, and they expressed their willingness to participate as part of the online survey. The Ministry of Health approved the study. The data was collected in the period from April to June 2018. The participation of all respondents was completely anonymous and voluntary. On the other hand, the electronic form of distribution ensures perfect anonymity and the possibility to reach a large number of respondents within the target population. As the study was targeted at the employees of healthcare facilities involved in the AESR pilot project, the authors assume a higher degree of compliance and reliability in responses.

\section{Statistical Analysis}

Statistical data processing was conducted in IBM SPSS Statistics version 22 using pivot tables and descriptive statistics. The analysis studied the significance in both categories (response rate percentage $\left.-\mathrm{p}^{\mathrm{K}}\right)$ and index $\left(\right.$ mean $\left.-\mathrm{p}^{\mathrm{I}}\right)$. The differences in the representation of responses between the compared groups, including the possibility of "not available", were tested using a maximum-likelihood chi-square test (results reported as $\mathrm{p}^{\mathrm{K}}$ ). The differences in the index values between the compared groups were evaluated using the Kruskal-Walis test (results reported as $\mathrm{p}^{\mathrm{I}}$ ). The records without any response were excluded from the evaluation.
The differences in responses between the compared groups were considered significant if $\mathrm{p}^{\mathrm{K}}$ and $\mathrm{p}^{\mathrm{I}}$ were $<0.05$.

\section{RESULTS}

The questionnaire was submitted by a total of 2,049 healthcare professionals from 80 inpatient healthcare facilities in the Czech Republic. The return rate of the questionnaire could not be determined due to the electronic form of distribution. Statistical processing was performed in 2,016 questionnaires due to the completeness of the data. The questionnaire was completed by 234 men (11.6\%) and 1,782 women (88.4\%). The average age of the respondents was 44 years, the median age was 44 years, and $50 \%$ of respondents $(25$ th -75 th percentile) were $36-53$ years old.

Table 1 shows the total number of respondents as per their medical specialty. According to job positions, the respondents were categorized into three groups: physicians, non-medical health workers at patient's bedside (NHP-B), i.e. general nurse, midwife, practical nurse/formerly medical assistant, auxiliary personnel, paediatric nurse, perioperative nurse, and other NHP (NHP-O), i.e. medical laboratory, radiological assistant, physiotherapist, health management, biomedical engineer, paramedic, nutritional therapist, pharmaceutical assistant, technical-economic worker, occupational therapist, speech therapist, pedagogue, psychologist, scientific researcher, manager, and dental assistant. Most respondents' work position was non-medical healthcare professional working at the patient's bedside $(73 \%)$, physician (16\%), and other non-healthcare staff (11\%).

The results of the survey are summarized in Table 2 . The highest declared level of compliance with the individual hygiene precautions was found in the statement "I discard used sharp materials in containers for sharp waste", in which $99 \%$ of respondents' answers included positive-scale items ("always," "often" and "usually"); for "I avoid the disassembling of a used needle from a syringe.", $97.5 \%$ of respondents chose a positive response spectrum, and for the statement "I wear gloves when the exposure of my hands to body fluids is anticipated." $98.7 \%$ of respondents selected a positive response. The lowest declared level of compliance with hygiene standards was identified in the following statements: "I use a face mask when exposure to air-transmitted pathogens is anticipated.", $84.8 \%$ of respondents selected the positive-scale responses, however, only $47.9 \%$ selected the option "always". Another item with a higher number of answers in the negative range ("sometimes", "seldom" or "never") was identified in the statement "I wash my hands after the removal of gloves." Hereby, $60.8 \%$ of respondents selected the option "always". In the state-

Table 1. Representation of individual clinical disciplines in the sample $(N=2,016)$

\begin{tabular}{|l|c|c|}
\hline Clinical discipline & $\mathbf{n}$ & $\%$ \\
\hline Surgery & 575 & 28.5 \\
\hline Internal medicine & 868 & 43.1 \\
\hline Psychiatry & 276 & 13.7 \\
\hline Other* & 297 & 14.7 \\
\hline
\end{tabular}

${ }^{*}$ These disciplines represent mixed specialities, e.g. long-term care facility, multidisciplinary, uncategorized. 


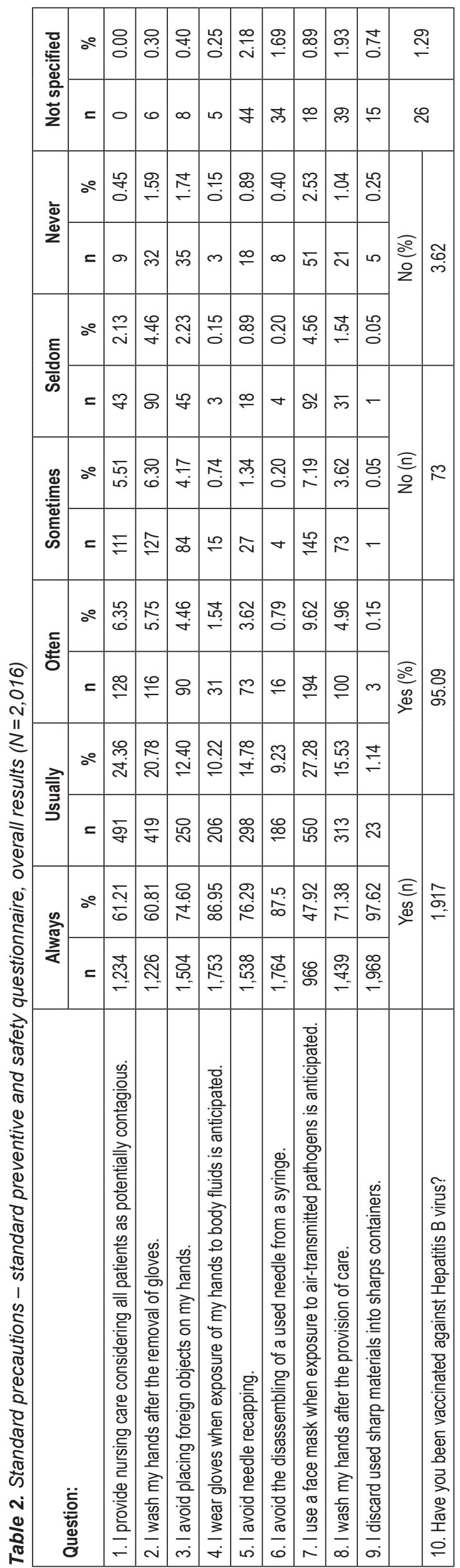

ment "I provide nursing care considering all patients as potentially contagious.", $8 \%$ of respondents selected a negative spectrum of responses (5.51\% for "sometimes", $2.13 \%$ for "seldom" and $0.45 \%$ for "never"), only $61.2 \%$ selected "always".

The overall response rates and scores for individual items are illustrated in Fig. 1.

Individual statements from the standardized part of the questionnaire as per the respondents' profession and specialty will be interpreted in the following text. The most significant results were identified in the following items. For the first item "I provide nursing care considering all patients as potentially contagious.", the negative spectrum was selected by $36 \%$ of physicians from psychiatric wards (20\% "sometimes", 12\% "seldom", 4\% "never"). The situation in NHP-B in psychiatric wards is slightly better. Only $12 \%$ of respondents chose the responses within the negative spectrum. There were significant differences between individual professions in internal wards $\left(\mathrm{p}^{\mathrm{K}}=0.010, \mathrm{p}^{\mathrm{I}}=0.001\right)$ and psychiatric wards $\left(\mathrm{p}^{\mathrm{K}}=0.002, \mathrm{p}^{\mathrm{I}}=0.039\right)$. For the other clinical disciplines and professions, the responses varied predominantly within the positive spectrum, with no significant differences between professions. In the statement "I wash my hands after the removal of gloves.", most respondents selected the options in the positive spectrum, as well. There were no significant differences between professions and medical specialties. In the third statement, "I avoid placing foreign objects on my hands.", most of the physicians from psychiatric wards $(40 \%$ in total; $16 \%$ "sometimes", $12 \%$ "seldom", $12 \%$ "never") and $20 \%$ of internal department physicians (9\% "sometimes", 4\% "seldom", $7 \%$ "never") opted for the responses within the negative scale. From all medical specialties and professions, the statistically significant differences have been identified in "wearing foreign objects" statement on the significance level $\mathrm{p}<0.001$ for summary index and on the significance level $\mathrm{p}<0.005$ for categories. The item "I wear gloves when exposure of my hands to body fluids is anticipated." has demonstrated relatively satisfactory results. The positive spectrum of answers was selected by $99 \%$ of all respondents (87\% “always", 10\% “usually”, 2\% “often"). No significant differences were identified between medical specialties and professions. For the statement "I avoid turning the needle up when handling the needle.", the respondents were predominantly selecting the positive range of options (76\% "always", $15 \%$ "usually" and 4\% "often"), having "never" (6\%) and "seldom" $(6 \%)$ the most frequent negative-scale responses in NHP-O in the internal field. Statistically significant differences were found between physicians, NHP-B and NHP-O in the internal department $\left(\mathrm{p}^{\mathrm{K}}=0.001, \mathrm{p}^{\mathrm{I}}=0.001\right)$. It should be taken into account that the results may be affected by the proportion of respondents who did not select any of the given options ( $2 \%)$. There were no significant differences in the responses between medical specialties and professions in the statement "I avoid the disassembling of a used needle from a syringe." The positive range of responses $(88 \%$ "always", $9 \%$ "usually", $1 \%$ "often") was selected by $98 \%$ of the respondents. Notable are the responses in the item "I use a face mask when exposure to air-transmitted pathogens is anticipated." The best response was identified in the group of employees from surgical fields, of which most opted for positive-scale answers: the statement was accepted by $92 \%$ of physicians ( $49 \%$ "always", $34 \%$ "usually" $9 \%$ "often"), $86 \%$ of NHP-B (45\% "always", $32 \%$ "usually" and 9\% "often") and 95\% of NHP-O (63\% "always", 

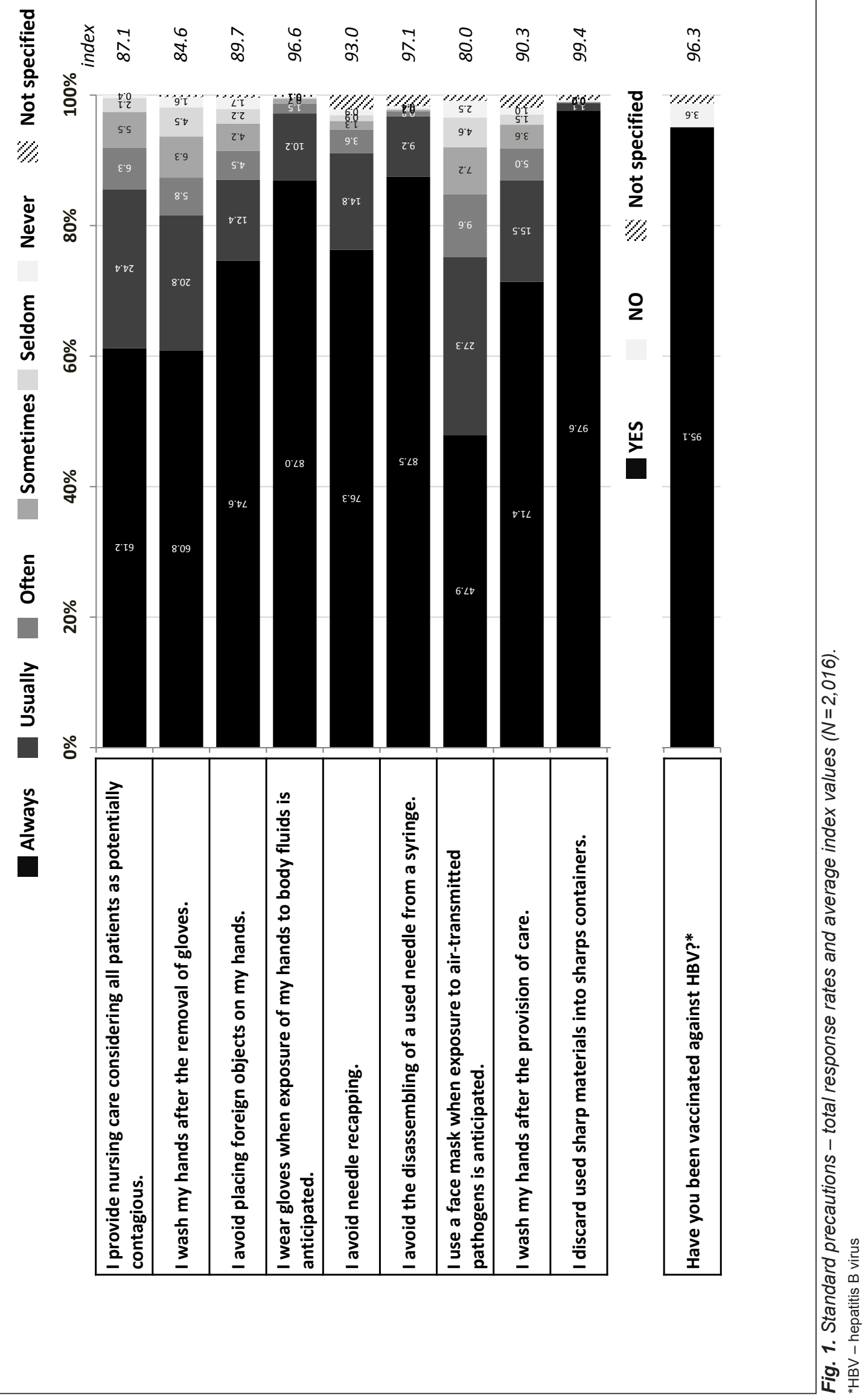


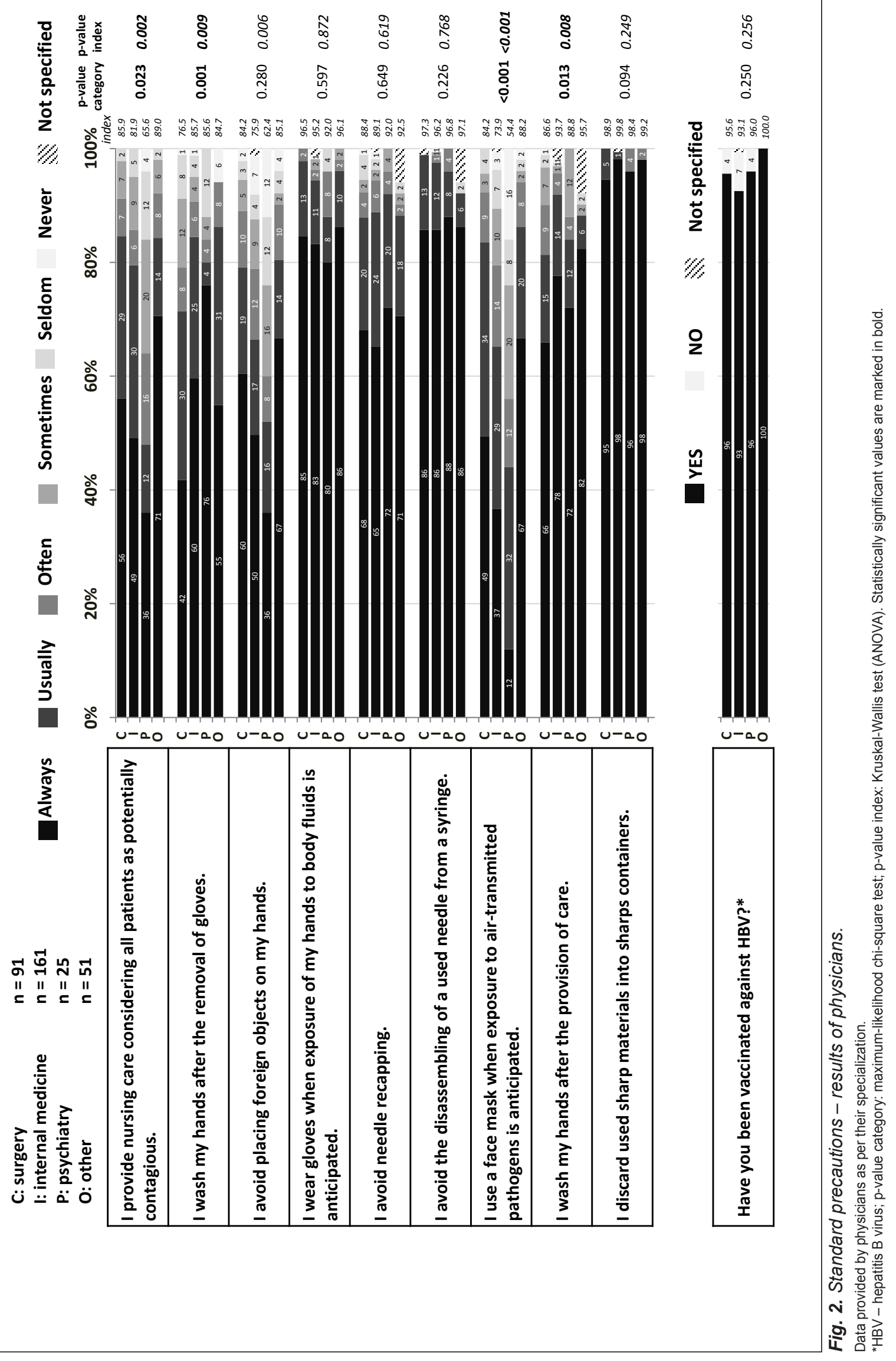




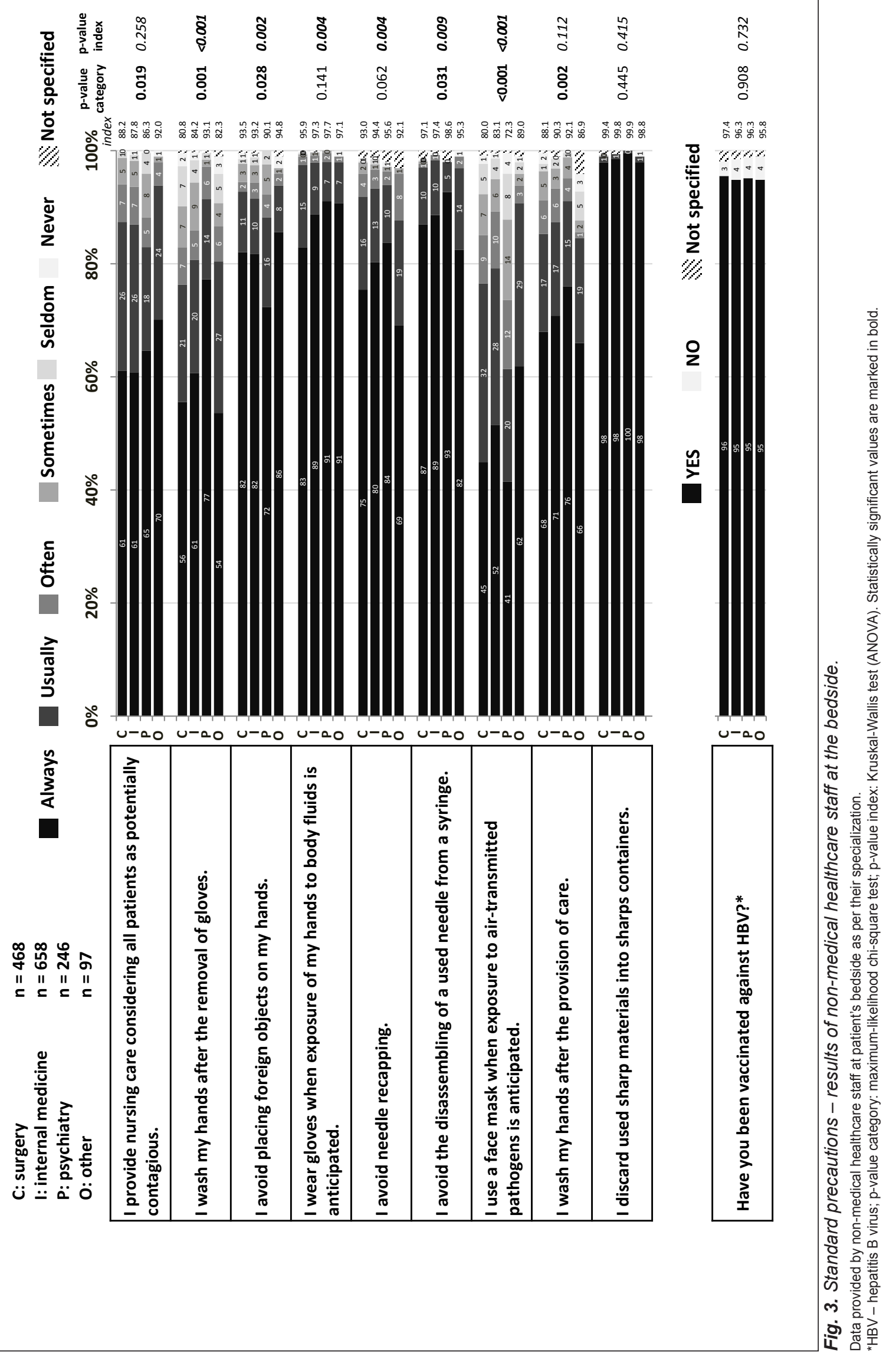


19\% "usually", 13\% “often"). The highest number of negative responses was identified in healthcare professionals in psychiatric wards who declared they had not been using the mouthpiece. For physicians, it was $20 \%$ selecting the option "sometimes", $8 \%$ with "seldom" and 16\% "never". Most respondents within the category of NHP-B in psychiatric wards indicated that they used the face mask (41\% "always", $20 \%$ "usually", and 12\% "often"). There is a rather significant proportion of respondents $(26 \%)$ who selected "sometimes" (14\%), "seldom" (8\%), and "never" (4\%) for the above-mentioned item. A relatively large proportion (40\%) of respondents from the category of NHP-O in psychiatric wards claimed rather sporadic use of face mask (20\% "sometimes", $20 \%$ "never"). Statistically significant differences between professions were identified in internal medicine $\left(\mathrm{p}^{\mathrm{K}}<0.001 ; \mathrm{p}^{\mathrm{I}}=0.002\right)$ and other fields $\left(\mathrm{p}^{\mathrm{K}}=0.017 ; \mathrm{p}^{\mathrm{I}}=0.003\right)$.

Most of the respondents (92\%) agreed with the statement "I wash my hands after the provision of care." (71\% opted for "always", $16 \%$ for "usually", and 5\% for "often"). Significant differences between professions were identified in the field of internal medicine $\left(\mathrm{p}^{\mathrm{K}}=0.009 ; \mathrm{p}^{\mathrm{I}}=0.041\right)$. In the last statement, "I discard used sharp materials into sharps containers.", the result can be considered positive since $98 \%$ of respondents selected the option "always". Statistically significant differences were again identified between the professions in the field of internal medicine $\left(\mathrm{p}^{\mathrm{K}}<0.001 ; \mathrm{p}^{\mathrm{I}}=0.002\right)$.

Compliance with hygiene standards carried out by physicians in different medical fields is shown in Fig. 2. The physicians' most frequent mistakes included wearing "foreign" objects on their hands (rings, watches, bracelets, etc.), not wearing a face mask when assuming contact with airborne pathogens and their statements that not everyone considered patients potentially infectious in their work. Descriptive statistics show the statements of physicians working in the psychiatric field prevail in the above negative phenomena. This was also demonstrated by statistical testing that identified significant differences between medical fields in the following statements: "I provide nursing care considering all patients as potentially contagious" $\left(\mathrm{p}^{\mathrm{K}}=0.023 ; \mathrm{p}^{\mathrm{I}}=0.002\right)$, "I wash my hands after removing used gloves." ( $\left.\mathrm{p}^{\mathrm{K}}=0.001 ; \mathrm{p}^{\mathrm{I}}=0.009\right)$, "I use a face mask when exposure to air-transmitted pathogens is anticipated." $\left(\mathrm{p}^{\mathrm{K}}=0.001 ; \mathrm{p}^{\mathrm{I}}=0.001\right)$ and in the item "I wash my hands after the removal of gloves." $\left(\mathrm{p}^{\mathrm{K}}=0.013 ; \mathrm{p}^{\mathrm{I}}=0.008\right)$.

In the category of non-medical healthcare staff working at the patient's bedside, positive results were reported in all medical fields (Fig. 3). NHP-B declare compliance with hygiene standards in handling and disposal of sharp objects. The most negative responses were related to the compliance with the prevention of airborne infections since less frequent use of face mask has been reported. In the NHP-B category, statistically significant differences were reported in the following categories of medical fields: "I wash my hands after the removal of gloves." Respondents in surgical and other fields reported the least frequent hand washing after the removal of gloves. However, the highest frequency of handwashing was reported in psychiatric departments $\left(\mathrm{p}^{\mathrm{K}}=0.001\right.$; $\left.\mathrm{p}^{\mathrm{I}}=0.001\right)$. Respondents from the psychiatric departments have proven a higher frequency for the statement "I avoid placing foreign objects on my hands." $\left(\mathrm{p}^{\mathrm{K}}=0.028 ; \mathrm{p}^{\mathrm{I}}=0.002\right)$. Statistically significant differences between the respondents from the individual departments were shown in the statement "I avoid the disassembling of a used needle from a syringe." $\left(\mathrm{p}^{\mathrm{K}}=0.031\right.$;
$\left.\mathrm{p}^{\mathrm{I}}=0.009\right)$. As it was in the statement "I use a face mask when exposure to air-transmitted pathogens is anticipated", respondents' answers varied significantly depending on the departments $\left(\mathrm{p}^{\mathrm{K}}=0.001 ; \mathrm{p}^{\mathrm{I}}=0.001\right)$.

Non-medical healthcare workers identified as others stated similar answers to the group of non-medical staff working at the patient's bedside. In some cases, the answers were not filled, which might result from the fact that particular respondents have not encountered the described situation in their professional life. This includes especially the items related to handling and disposal of needles and sharp objects, as well as the specific interventions related to direct patient care. Statistically significant differences were not confirmed in any of the categories or indices. For this reason, we do not describe them in further details. The results are graphically summarized in Fig. 4.

The overall results of the standardized questionnaire evaluation also affect the other analysed areas of this study (Table 3). As for age, the statistical testing proved the dependency in all observations (significance level $\mathrm{p}<0.05$ ), i.e. the increasing age is linked with the increased compliance rate, except in the items "I use a face mask when exposure to air-transmitted pathogens is anticipated." $\left(\mathrm{p}^{\mathrm{K}}=0.588 ; \mathrm{p}^{\mathrm{I}}=0.080\right)$, and "I discard used sharp materials into sharps containers." $\left(\mathrm{p}^{\mathrm{K}}=0.376 ; \mathrm{p}^{\mathrm{I}}=0.130\right)$. In case of gender, statistically significant dependence has been demonstrated in the statement "I avoid placing foreign objects on my hands" ( $\left.\mathrm{p}^{\mathrm{K}}=0.001 ; \mathrm{p}^{\mathrm{I}}=0.001\right)$, "I avoid the disassembling of a used needle from a syringe." $\left(\mathrm{p}^{\mathrm{K}}=0.001 ; \mathrm{p}^{\mathrm{I}}=0.001\right)$, and " $\mathrm{I}$ discard used sharp materials into sharps containers" $\left(\mathrm{p}^{\mathrm{K}}=0.041\right.$; $\left.\mathrm{p}^{\mathrm{I}}=0.021\right)$. In all of the above-mentioned items, higher compliance with hygiene standards was confirmed in women. Education significantly affects the results in five of nine items. More specifically: "I wash my hands after the removal of gloves." $\left(\mathrm{p}^{\mathrm{K}}=0.001 ; \mathrm{p}^{\mathrm{I}}=0.001\right)$, "I avoid placing foreign objects on my hands" ( $\left.\mathrm{p}^{\mathrm{K}}=0.001 ; \mathrm{p}^{\mathrm{I}}=0.001\right)$, "I avoid needle recapping." $\left(\mathrm{p}^{\mathrm{K}}\right.$ $\left.=0.001 ; \mathrm{p}^{\mathrm{I}}=0.001\right)$, "I avoid the disassembling of a used needle from a syringe." $\left(\mathrm{p}^{\mathrm{K}}=0.007 ; \mathrm{p}^{\mathrm{I}}=0.010\right)$, and "I wash my hands after the provision of care." $\left(\mathrm{p}^{\mathrm{K}}=0.048 ; \mathrm{p}^{\mathrm{I}}=0.004\right)$. Respondents with higher education reported more frequent compliance with standard precautions. The relation between years of practice and adherence to standards showed significant differences between respondents in all statements ( 6 items at significance level $\mathrm{p}<0.01$ and 1 item at significance level $\mathrm{p}<0.05$ ) except for "I use a face mask when exposure to air-transmitted pathogens is anticipated" $\left(\mathrm{p}^{\mathrm{K}}=0.273 ; \mathrm{p}^{\mathrm{I}}=0.101\right)$, and "I discard used sharp materials into sharps containers." $\left(\mathrm{p}^{\mathrm{K}}=0.303 ; \mathrm{p}^{\mathrm{I}}=0.066\right)$. As the number of years of practice increased, compliance with hygiene standards was reported more frequently. Significant differences were also reported among the respondents of various healthcare professions: physicians, NHP-B, NHP-O (Table 3).

\section{Limitation of the Study}

The electronic form of the questionnaire distribution and completion was, to a certain extent, also a limitation of the study since the authors could not guarantee complete and unbiased outcome from the respondents.

The whole spectrum of the healthcare workers within the ones not working directly at the patient's bedside was included in the analysis. This fact can be considered as a possible limitation 


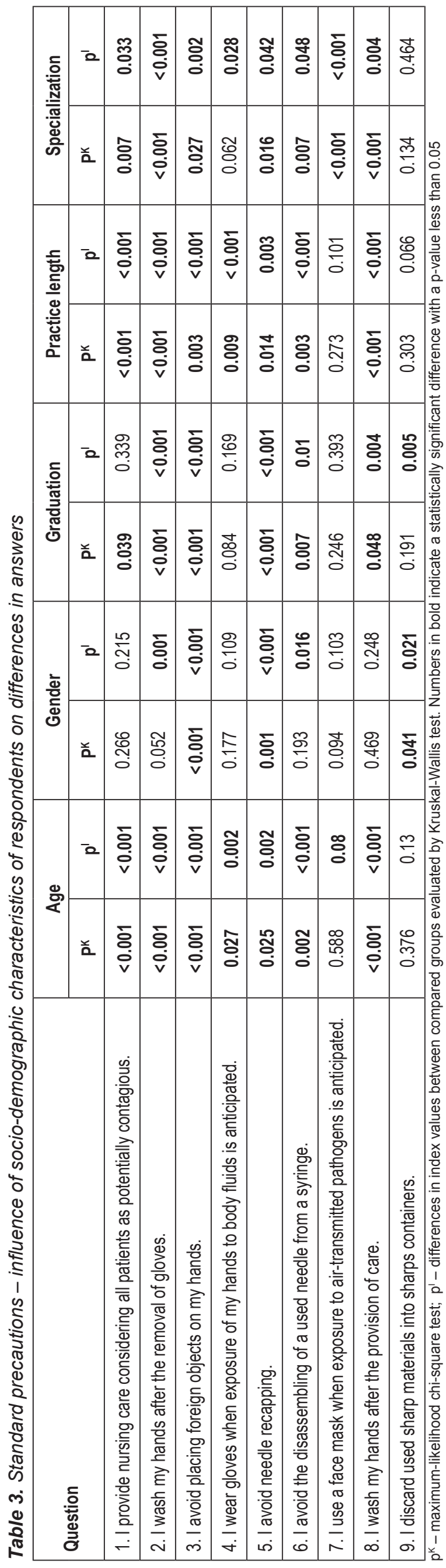

of the study. Another limitation is the relatively small ration of respondents per healthcare provider as it comes out around 25 workers representing one healthcare provider. There is also a low number of responding physicians.

\section{DISCUSSION}

Generally, the overall results of the questionnaire survey may be considered positive. Based on the declared statements, the respondents from clinical practice did not prove any fundamental deficiencies in terms of compliance with standard precautions in healthcare facilities in the Czech Republic. The lowest rating (80.0 points) was reported by all respondents in the statement "I use a face mask when exposure to air-transmitted pathogens is anticipated." The recommendation to use a face mask when the exposure to respiratory pathogens is anticipated is given by the WHO document (Standard Precautions in Health Care) (7). The highest rating index ( 99.4 points) was registered in the statement "I discard used sharp materials into sharps containers.", suggesting that almost all respondents confirmed adherence to the guidelines on handling sharp objects (8). All other analysed hygiene standards identified the index between 80.0 and 99, indicating that the most frequent answers included the options "always" (100 points) and "usually" (80 points). It is also worth mentioning that within all profession categories, the respondents indicated that they do not know if they are vaccinated against hepatitis B. In the Czech Republic, this is mandatory for all healthcare professionals (9). Higher frequency of selecting the answers within the negative spectrum ("sometimes", "seldom" and "never") has been identified in the statement "I wash my hands after the removal of gloves.", where only $60.8 \%$ of respondents chose the option "always". In this context, the Czech Republic has a different recommendation when comparing to the international guidelines. The use of gloves within the Czech legislative context (or the context of internal regulations of individual medical facilities) remains subject to discussion. Internal regulations usually indicate no necessity to wash hands after removing used gloves unless they have been damaged when handling infectious material or used for direct patient intervention $(10,11)$. In the statement "I avoid placing foreign objects on my hands.", $40 \%$ of psychiatric ward physicians and $20 \%$ of internal ward physicians claimed they did not follow the policy of not wearing foreign objects on their hands (half of the psychiatrists and one-fifth of internal medicine physicians) and thus acted contrary to the recommendations $(8,11)$. Other non-medical professionals very often did not state any response, especially in the items related to direct contact with patients or sharp objects handling. This is probably because they have not encountered these situations in their regular work (i.e. they do not handle sharp objects or are not involved in direct patient care). We compared our findings with the study focused on compliance with standard preventive measures in resident physicians in gynaecology and obstetrics using a comparable standardized questionnaire "Standard precautions adherence scale" containing 13 items (12). The authors present that only $19 \%$ of physicians in their study confirmed compliance with hygiene standards regardless of the patient's diagnosis. As it was in our survey, the respondents claimed precaution when handling sharp objects. 


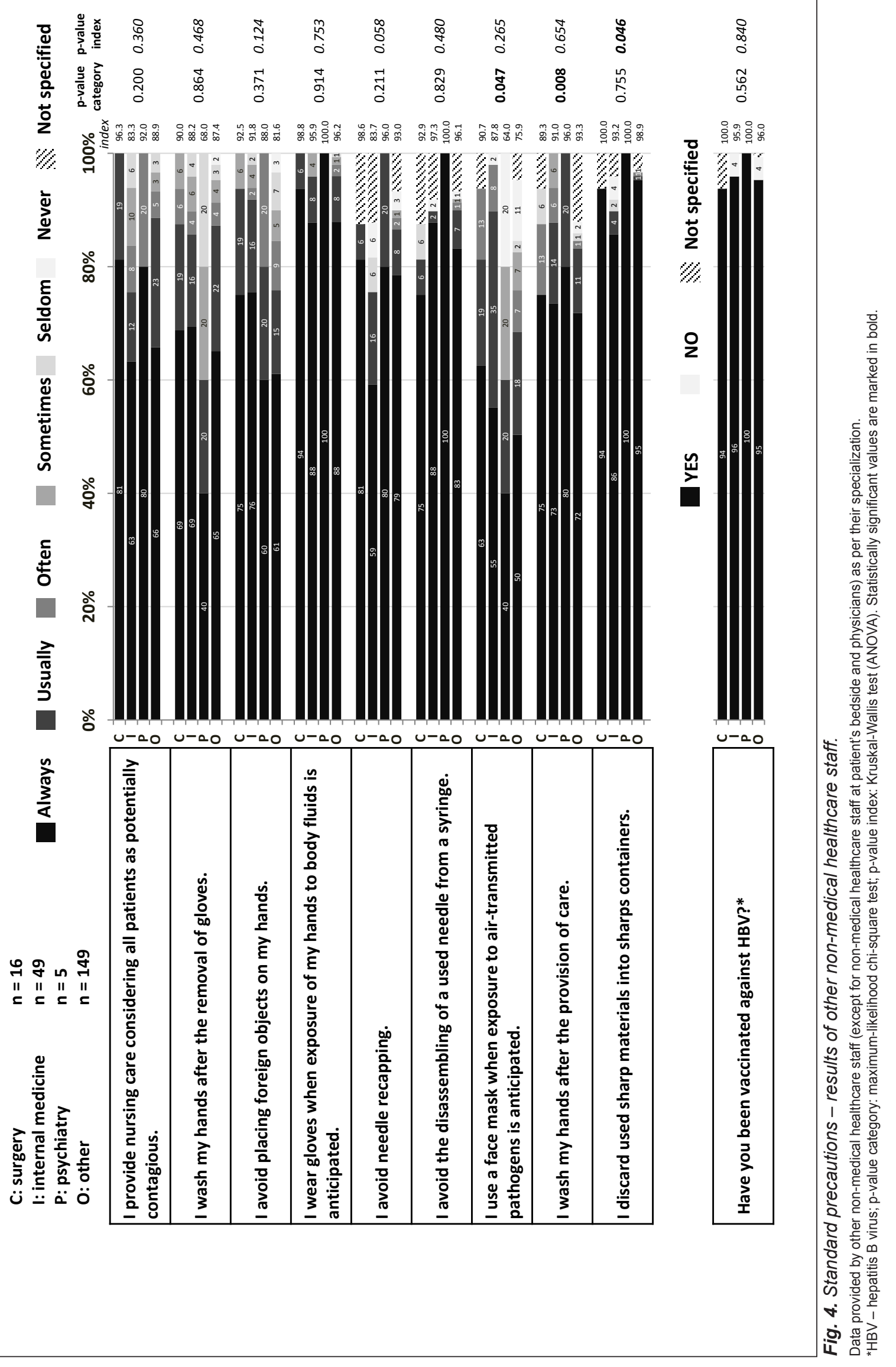


In France, a study was conducted using a ten-item knowledge questionnaire focused on adhering to standard precaution measures. A total of 4,439 questionnaires were analysed. The largest group of respondents included nurses $(44.1 \%)$, medical assistants $(26.7 \%)$, and physicians $(3.5 \%)$. Only $25 \%$ of respondents reported having attended specific standard precautions training within the past five years. The percentage of correct answers for each question ranged from $37.1 \%$ to $91 \%$. The most frequent correct responses were related to hand hygiene (72.6\%), however, only $7.3 \%$ of correct responses were related to use of appropriate precautions in needle care and disposal (13). In this case, the difference between the respondents in our study is notable. Only $39.3 \%$ of French respondents correctly answered eight or more of the 10 questions in the questionnaire. Overall, nurses demonstrated to have a higher level of knowledge when compared to other healthcare professionals. The lowest level of knowledge was identified in long-term care institutions and psychiatric hospitals (13). The results thus confirm our findings in the Czech Republic.

Another study conducted by nursing students in Saudi Arabia highlights the importance of adherence to infection and prevention control at university hospitals (14). Nursing students considered infection prevention during their clinical practice slightly positive and showed moderate compliance with standard precautions. Items like age, year of study, or participation in the course dedicated to the prevention and management of infections in clinical practice have been identified as important factors affecting the compliance of nursing students with hygiene standards. The influence of the age and profession on the overall results of healthcare workers' compliance with standard precautions has also been proven significant in the study by Ngwa et al. (4). Again, analogically to our research, higher compliance with standard precautions has been reported with increasing age and higher education. The reasons for not following hygiene standards are mentioned in similar research in which only $22 \%$ of respondents were convinced that discontinuing the use of standard precaution measures would pose a threat to the patient (15). Therefore, it is evident that the area of prevention was downplayed by respondents in clinical practice although, in terms of risk situations and pathogen exposure, $34 \%$ of respondents reported sharp object injuries in the previous three months and $42 \%$ reported that they were demonstrably exposed to droplets infections. In terms of overall inconsistency, $44 \%$ of respondents used gloves less than $100 \%$ of the time and $61 \%$ washed their hands less than $100 \%$ of the time. In another study, gender differences were observed in the implementation of standard precautions focused on blood-borne pathogens among surgeons. The study sample included a total of 241 respondents, $179(74.3 \%)$ men and $62(25.7 \%)$ women, $30.3 \%$ of the surgeons claimed they were extremely concerned about being exposed to a risk of getting human immunodeficiency virus within the scope of their occupation, and yet they had never tried to use double-gloving protection $(\mathrm{p}=0.027)$. Generally, men followed the standard precautions less frequently than women (16), especially in surgeries with higher risks of infection transmission. This finding is in line with our findings, where gender differences were also identified. We should emphasize the aspect of the feminization in the healthcare system, as well as gender distribution in the investigated group. Based on a statistical analysis of the data, there are significant differences between men and women regarding compliance with standard precautions.
The relation between years of practice and adherence to standard safety practices has not been demonstrated in all investigated studies (17). A profoundly influencing factor for the level of standard precautions is the years of experience, as seen in the study published by Rosinski et al. (3), in which the respondents with fewer years of practice showed a higher level of compliance than those with longer practice. The greatest decrease in adherence to standard precautions was identified between 3 and 8 years of practice. It was also shown that respondents working in the standard departments and the intensive care units showed lower levels of compliance with hygiene standards. Significantly highest adherence to hygiene standards has been demonstrated in respondents working in emergency departments (3). Hereby, the results of Rosinski's study are in line with our findings, as we have also identified significant differences in declared procedures among respondents with shorter and longer periods of experience. In our study, respondents with longer practice reported more frequent adherence to hygiene standards. Correspondingly, the results of Fenclová (2) show that the workers most often become ill with an occupational disease in the first four years after taking up the employment. In a questionnaire study by Powers et al. (18), having a similar design to our research with an added entry for hepatitis $\mathrm{C}$ virus (HCV), it was found that $17.4 \%$ of nurses claimed to be "always in compliance" with all 9 compliance items of standard precautions, $92 \%$ of respondents claimed they were wearing gloves, and $70 \%$ were always wearing a face mask. More than $16 \%$ of respondents in this study stated they sometimes or seldom avoided wearing foreign objects on their hands.

Although we stated that we considered the findings of our research positive, it would be useful to further discuss the improvements, or at least the ways to maintain the current status. One of the solutions may include regular training sessions on infection and prevention control for healthcare forces. The positive effects of education/training have been repeatedly demonstrated in several studies (19-22). The sectoral safety objective of the Ministry of Health of the Czech Republic is also devoted to the issue of introducing optimal procedures for hand hygiene during health care provision. One of the ways to increase the knowledge of standard hygiene measures is also the use of educational videos. It has been shown that educating health professionals through an educational video is more effective for improving the knowledge of standard precautions than learning by reading (23). Standardized precautions and hygiene regulations are the most important measures to prevent and control infections, to reduce the transmission of microorganisms to patients or healthcare providers (24). Healthcare operation managers should pay more attention to monitor compliance with standard precautions in healthcare professionals to effectively implement and evaluate interventions as per the needs of clinical practice (25). It is also appropriate to schedule regular preparation, evaluation, development, and implementation of guidelines to improve the theoretical and practical knowledge of healthcare professionals about infection prevention and control (26).

\section{CONCLUSION}

The essential element in promoting safe treatment, prevention, and infection control of treatment-related infections shall be the 
support of healthcare professionals in following the standard precautions. In our questionnaire survey, we verified that compliance with standard precautions is declared to be at a satisfactory level in selected healthcare facilities in the Czech Republic $(\mathrm{N}=80)$. In clinical practice, the respondent group $(\mathrm{N}=2,016)$ did not identify major deficiencies in compliance with hygiene standards. Most deficiencies have been linked to the declared use of face mask if any potential contact with airborne/droplet-borne pathogens is assumed. On the contrary, the best agreement in terms of the safety measures observance was found during handling and disposal of sharp material, which, according to respondents, is always thrown into containers intended for sharp waste. The level of declared compliance with standard precautions is influenced by age, years of practice, gender, field of medicine, profession, and level of education. We found a higher level of compliance with standard precautions in respondents with higher age, more extended clinical experience, and a higher level of education, in the group of non-medical healthcare workers and women. All participating hospital representatives (mainly quality managers) were provided with feedback for the possibility of implementing corrective measures, especially with regard to the fact that some findings were alarming and may endanger the health of patients and caregivers.

\section{Acknowledgements}

The authors thank to all medical personnel involved in the study.

\section{Conflict of Interests}

None declared

\section{REFERENCES}

1. Zatloukalová S, Holý O, Kollárová JH. Occupational infections in health care professionals in the Czech Republic in 2008-2015. Prac Lek. 2017;69(1-2):27-36. (In Czech.)

2. Fenclová $Z$. Health care professionals and occupational diseases in the Czech Republic. Med Praxi. 2009;6(2):69-71. (In Czech.)

3. Rosiński J, Różańska A, Jarynowski A, Wójkowska-Mach J; Polish Society of Hospital Infections Team. Factors shaping attitudes of medica staff towards acceptance of the standard precautions. Int J Environ Res Public Health. 2019 Mar 23;16(6):1050. doi: 10.3390/ijerph16061050.

4. Ngwa CH, Ngoh EA, Cumber SN. Assessment of knowledge, attitude and practice of health care workers in Fako Division on post-exposure prophylaxis to blood borne viruses: a hospital based cross-sectional study. Pan Afr Med J. 2018 Oct 12;31:108. doi: 10.11604/pamj.2018.31.108.15658.

5. Efstathiou G, Papastavrou E, Raftopoulos V, Merkouris A. Compliance of Cypriot nurses with standard precautions to avoid exposure to pathogens. Nurs Health Sci. 2011;13(1):53-9.

6. Pokorná A, Štrombachová V, Mužík J, Búřilová P, Kučerová J, Pospíšil $\mathrm{M}$, et al. National portal System for reporting adverse events [Internet]. Prague: Institute of Health Information of the Czech Republic; 2016 [cited 2019 July 17]. Available from: https://shnu.uzis.cz/. (In Czech.)

7. World Health Organization. Standard Precautions in Health Care 2007 [Internet]. Geneva: WHO; 2016 [cited 2019 July 10]. Available from: https://www.who.int/csr/resources/publications/EPR_AM2_E7.pdf.

8. Decree no. 306/2012 Coll. of 12 September 2012 on the conditions for the prevention and infectious disease control and on hygiene requirements for the operation of health care facilities and for social care institutions. Sbírka zákonů ČR. 2012;(109):3954-84. (In Czech.)
9. Decree no. 355/2017, amending Decree no. 537/2006 Coll., on vaccination against infectious diseases, as amended. Sbírka zákonů ČR. 2017;(123):3898-3900. (In Czech.)

10. Podstatová R. Hand hygiene for accreditation of healthcare institutions. Sestra. 2009;19 (10):39. (In Czech.)

11. Guideline 5/2012 Hand hygiene in healthcare. Věstník MZ ČR. 2012;(5):15-21. (In Czech.)

12. Milton JC, Fernanda MVP, Elucir G, Ching Lam S, Parente Barbosa C. Investigating compliance with standard precautions during residency physicians in gynecology and obstetrics. Clinics (Sao Paulo). 2016;71(7):38791.

13. Atif ML, Brenet A, Hageaux, Fave MH, Cochet C, Baticle E, et al Awareness of standard precautions for 4439 healthcare professionals in 34 institutions in France. Med Mal Infect. 2013;43(1):10-6.

14. Cruz JP, Colet PC, Al-Otaibi JH, SS Soriano, GM Cacha, Cruz CHP. Validity and reliability assessment of Standard Precautions Scale Arabic version in Saudi nursing students. J Infect Public Health. 2016;9(5):64553.

15. Ferguson KJ, Waitzkin H, Beekmann SE, Doebbeling BN. Critica incidents of nonadherence with standard precautions guidelines among community hospital-based health care workers. J Gen Intern Med. 2004;19(7):726-31.

16. Alsaigh SY, Alasmari AA, Hakeem AH, AF Aloushan, Saleh FS, Althubaiti A, et al. Gender differences in practicing standard precautions against blood-borne pathogens among surgeons at a tertiary care center: A cross-sectional study. Avicenna J Med. 2019;9(1):15-22.

17. LA Ferreira, CA Peixoto, L Paiva, Silva QCG, MP Rezende, Barbosa $\mathrm{MH}$. Adherence to standard precautions in teaching hospital. Rev Bras Enferm. 2017;70(1):96-103.

18. Powers D, Armellino D, Dolansky M, and Fitzpatrick J. Factors influencing nurse compliance with Standard Precautions. Am J Infect Control. 2016;44(2):4-7.

19. Siegel JD, Rhinehart E, Jackson M, L Chiarello. Guideline for Isolation Precautions: Preventing Transmission of Infectious Agents Healthcare Settings [Internet]. The Healthcare Infection Control Practices Advisory Committee; 2007 [cited 2017 Jun 10]. Available from: http://www.cdc. gov/ncidod/dhqp/pdf/isolation2007.pdf.

20. Goyal M, Chaudhry D. Impact of educational and training programs on knowledge of healthcare students regarding nosocomial infections, standard precautions and hand hygiene: a study at tertiary care hospital. Indian J Crit Care Med. 2019;23(2):227-31.

21. Baccolini V, D'Egidio V, Soccio P, Migliara G, Massimi A, Alessandri $\mathrm{F}$, et al. Effectiveness over time of multimodal intervention to improve compliance with standard hygiene precautions in an intensive care unit of a large teaching hospital. Antimicrob Resist Infect Control. 2019;31(8):92. doi: 10.1186/s13756-019-0544-0.

22. Sadeghi R, Hashemi M, Khanjani N. The impact of educational intervention based on health belief model observing standard precautions among emergency centers in Sirjan, Iran. Health Educ Res. 2018;33(4):327-35.

23. Wolfensberger A, Anagnostopoulos A, Clack L, Meier MT, Kuster SP, Sax H. Effectiveness of an edutainment video teaching standard precautions - a randomized controlled evaluation study. Antimicrob Resist Infect Control. 2019 May 22;8:82. doi: 10.1186/s13756-019-0531-5.

24. Jeihooni AK, Kashfi SH, Bahmandost M, Afzali Harsini P. Invest Educ Enferm. 2018;36 (1):e09. doi: 10.17533/udea.iee.v36n1e09.

25. Donati D, Biagioli V, Cianfrocca C, De Marinis MG, Tartaglini D. Compliance with standard precautions among clinical nurses: validity and reliability of the Italian Version of the Compliance with Standard Precautions Scale (CSPS-It). Int J Environ Res Public Health. 2019 Jan 4;16(1):121. doi: 10.3390/ijerph16010121.

26. Niraula Shrestha GD, Thapa B. Knowledge and practice on infection prevention among nurses of Bir Hospital. J Nepal Health Res Counc. 2018;16(3):330-5. 